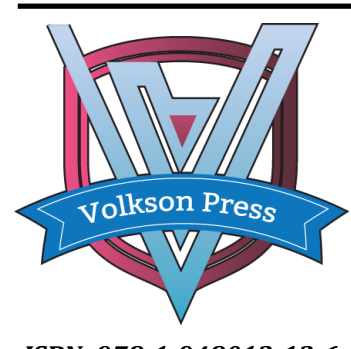

Contents List available at VOLKSON PRESS

New Materials and Intelligent Manufacturing (NMIM)

DOI : http://doi.org/10.26480/icnmim.01.2018.133.135

Journal Homepage: https://topicsonchemeng.org.my/

ISBN: 978-1-948012-12-6

\title{
THEORETICAL STUDIES ON THE STRUCTURES AND SPECTROSCOPIC PROPERTIES OF IR COMPLEXES WITH THE BIPYRIDYL-PHENYLENEDIAMINE LIGAND
}

\author{
Jianpo Zhang, Ying Wang, Junbo Zang, Yuhe Miao, Yue Sun, Li Jin* \\ School of Chemical and Pharmaceutical Engineering, Jilin Institute of Chemical Technology, Chengde Street 45\#, Jilin, China. \\ *Corresponding Author Email: lijin@jlict.edu.cn.
}

This is an open access article distributed under the Creative Commons Attribution License, which permits unrestricted use, distribution, and reproduction in any medium, provided the original work is properly cited

\section{ARTICLE DETAILS}

\section{Article History:}

Received 26 June 2018 Accepted 2 July 2018

Available online 1 August 2018

\section{ABSTRACT}

\begin{abstract}
The phosphorescent iridium(III) complexes $\left(\mathrm{N}^{\wedge} \mathrm{C}\right)_{2} \operatorname{Ir}(\mathrm{bpy}-\mathrm{D})$ (bpy-D = 4-(N-(2-amino-5- methoxyphenyl)aminomethyl)-4'-methyl-2,2'-bipyridine: $\mathrm{N}^{\wedge} \mathrm{C}=\mathrm{F}-\mathrm{ppy}(\mathbf{1}), \operatorname{ppy}(\mathbf{2}), \operatorname{pq}(\mathbf{3}), \operatorname{pqe}(\mathbf{4}) ; \mathrm{F}-\mathrm{ppy}=2-(2,4-$ difluorophenyl)pyridine, $\mathrm{ppy}=2$-phenylpyridine, $\mathrm{pq}=2$-phenylquinoline, $\mathrm{pqe}=2$-phenylcinchoninic acid methyl ester) were explored using density functional theory (DFT) methods. The optimized geometry structural parameters of the complexes in the ground state agree well with the corresponding experimental values. The lower-lying unoccupied molecular orbitals of complexes 1-4 are dominantly localized on the bidentate ligand, while the higherlying occupied ones are also composed of bidentate ligand. The lowest energy absorptions at 513, 506, 526, and 569 $\mathrm{nm}$ are attributed to a $\pi \pi^{*}$ transition, while their phosphorescence emission at 551, 619,642, and $659 \mathrm{~nm}$ have similar transition properties. This indicates that the phosphorescent color of lowest-energy emissions of these complexes could be tuned, could be altered by adjusting the $\pi$ electron-donating ability of $\mathrm{N}^{\wedge} \mathrm{C}$ ligand.
\end{abstract}

\section{KEYWORDS}

Iridium (III) complexes, Spectroscopic properties, Electronic Structures, TD-DFT

\section{INTRODUCTION}

In the last few decades, phosphorescent transition-metal complexes have been widely applied in organic light emitting devices, solar energy conversion, luminescence sensing, biotechnology and electroluminescence displays, because of facilitate strong electroluminescence by harnessing both singlet and triplet excitons [1-3]. Among these transition metal complexes, Ir complexes are the most tunable and effective, a lot of $\operatorname{Ir}$ complexes such as $\left(\mathrm{C}^{\wedge} \mathrm{N}\right)_{2} \operatorname{Ir}\left(\mathrm{O}^{\wedge} \mathrm{O}\right)$ have been synthesized by a group researchers [4]. The present results indicate that these complexes exhibit high quantum efficiencies and long radiative lifetime, the lowest-energy absorptions are all assigned to the metal-toligand charge transfer transition, and the highest-lying absorption are dominantly assigned to a $\pi-\pi^{*}$ excitation.

Recently, Lo and co-workers have prepared a series of $\left(\mathrm{N}^{\wedge} \mathrm{C}\right)_{2} \operatorname{Ir}($ bpy-D) complexes, they found that these complexes show interesting photophysical behavior and modification of these complexes with an ophenylenediamine unit will generate a new class of phosphorescent molecular probes for NO [5]. Although there have been many experimental studies on the photophysical and photochemical properties of these luminescent Ir(III) complexes, there are few corresponding theoretical reports on these complexes. Therefore, we performed theoretical calculations on (F-ppy) $)_{2} \operatorname{Ir}(\text { bpy-D)(1), (ppy) })_{2} \operatorname{Ir}\left(\right.$ bpy-D)(2), (pq) ${ }_{2} \operatorname{Ir}($ bpyD)(3), and (pqe) ${ }_{2} \operatorname{Ir}($ bpy-D)(4) in the ground- and excited states by DFT method.

\section{COMPUTATIONAL DETAILS AND THEORY}

The structures of iridium complexes 1-4 as shown in Figure 1. The geometry of the ground- and excited state structure is fully optimized by using the density functional theory (DFT) with the Perdew-BurkeErzenrhof (PBE0) and unrestricted PBE0 functional, respectively [6]. With such calculations, the absorption and emission spectra are obtained by the time dependent density functional theory (TD-DFT) associated with the polarized continuum model (PCM). This kind of theoretical approach has been proven to be reliable for transition metal complex systems such as $\left[\mathrm{RuL}_{2}(\mathrm{NCS})_{2}\right]^{4-}$ complexes. In the calculations, quasirelativistic pseudopotentials of the Ir atom proposed by Hay and Wadt with 17 valence electron were employed, and the 6-31G basis set was adopted for other atoms. All of the calculations were accomplished by using Gauss09 software package on an Sugon A840-G10 server.

\section{RESULTS AND DISCUSSION}

\subsection{The geometries of ground and excited states}

For complex 1, The calculated bond distances of Ir-N(bpy-D), Ir-N(F-ppy), and Ir-C are 2.181, 2.079, and $2.030 \AA$, the bond angles of N(bpy-D)-Ir$\mathrm{N}\left(\right.$ bpy-D) are $75.7^{\circ}$, the dihedral angle of N(bpy-D)-N(bpy-D)-Ir-N(F-ppy) is $86.1^{\circ}$, respectively. The three bidentate ligands planes are almost perpendicular to each other with the dihedral angles close to $90^{\circ}$. The analogous structures are also observed in 2-4.

The geometry parameters of lowest-lying triplet excited state of $\mathbf{1 - 4}$, which show similar tendency, have not vary notably relative compared with their ground state. Take 1 for example, the calculated Ir-N(bpy-D) bond lengths relax by $0.017 \AA$, but the Ir-N(F-ppy) and Ir-C bond lengths strengthen by $0.006 \AA$. This indicates that enhance the interaction between Ir atom and bpy-D ligand, and weak the interaction between Ir atom and $\mathrm{N}^{\wedge} \mathrm{C}$ ligand upon excitation. 


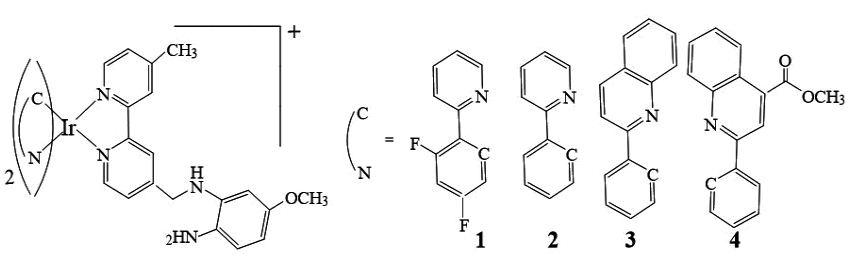

Figure 1: The structures of iridium complexes 1-4

\subsection{Absorptions spectra of 1-4 in the ground states}

From Figure 2, the absorption spectra of 1-4 show three absorption bands, the most representative optical transitions and their oscillator strengths, the main configurations, their assignments are given in Table 1. A detail analysis of the frontier orbital compositions and energies of $\mathbf{1}$ and $\mathbf{4}$ is presented in Tables 2 and 3.

Table 1 show the lowest-lying absorptions of $\mathbf{1 - 4}$ at 513(2.41), 506(2.45), $526(2.35)$, and $569 \mathrm{~nm}(2.18 \mathrm{eV})$, respectively. With respect to 1 , the excitation of MOs $190 \rightarrow 191$ is dominantly responsible for the absorption band at $513 \mathrm{~nm}$. Table 2 shows that MOs 190 and 191 are dominantly localized on bpy-D ligand (100\% and $94.6 \%)$. Thus, the absorption at 513 $\mathrm{nm}$ for 1 can be assigned to a $\pi\left(\right.$ bpy-D) $\rightarrow \pi^{*}$ (bpy-D) transition with ILCT transition characters. In the meantime, the transition path of the lowestenergy absorption of $\mathbf{2}$ is similar to that of $\mathbf{1}$. But the absorptions of $\mathbf{3}$ and 4 at 526 and $569 \mathrm{~nm}$ has different character. The only difference is the contributes of the ligand composition from the $\mathrm{N}^{\wedge} \mathrm{C}$, thus the absorptions of $\mathbf{3}$ and $\mathbf{4}$ can be described as originating from the $\pi(b p y-D) \rightarrow \pi^{*}\left(C^{\wedge} N\right)$ excited state with different LLCT character. By comparing the excitation energies of 1-4, we found that the lowest-lying absorption is red-shifted from $1 \sim 2<3<4$, which is consistent with the increasing trend of the $\pi$ donating ability.

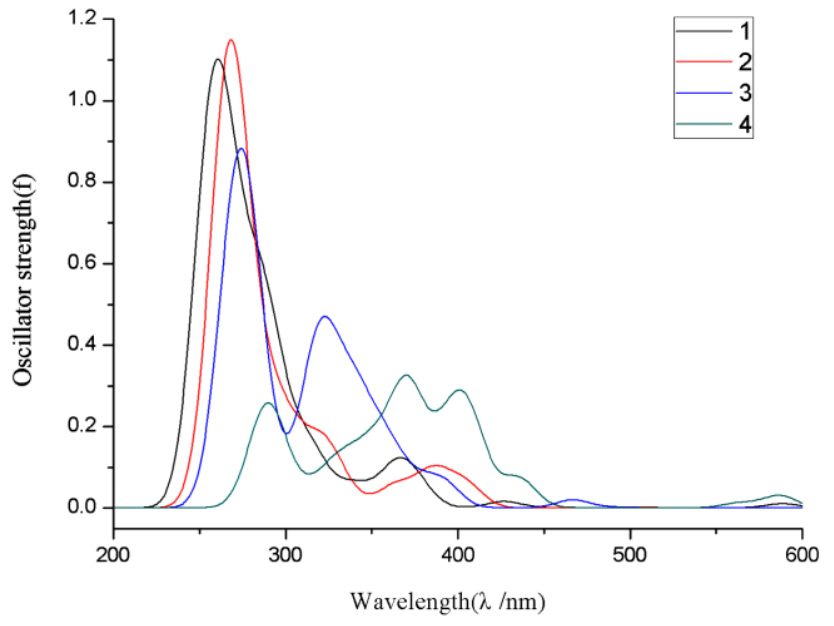

Figure 2: Gaussian curve simulated absorption spectra of 1-4 in $\mathrm{CH} 2 \mathrm{Cl} 2$ media

Table 1: Absorptions spectra of 1-4 in $\mathrm{CH} 2 \mathrm{Cl} 2$ media under TD-DFT calculations, together with experimental values

\begin{tabular}{|llllll|}
\hline & Transition and Config & $\lambda_{\text {cal }}(\mathrm{nm})$ & Oscillator & Assignment & $\lambda_{\text {exptt }}(\mathrm{nm})^{[5]}$ \\
\hline $\mathbf{1}$ & $190 \rightarrow 191(0.70)$ & $513(2.41)$ & 0.0100 & ILCT & \\
& $187 \rightarrow 191(0.54)$ & $362(3.42)$ & 0.0690 & MLCT/LLCT & 366 \\
$\mathbf{2}$ & $187 \rightarrow 197(0.45)$ & $260(4.77)$ & 0.2972 & MLCT $/$ ILCT & 267 \\
& $174 \rightarrow 175(0.52)$ & $506(2.45)$ & 0.0009 & ILCT & \\
& $171 \rightarrow 175(0.62)$ & $385(3.22)$ & 0.1503 & MLCT/LLCT & 381 \\
& $169 \rightarrow 179(0.52)$ & $267(4.64)$ & 0.2589 & MLCT/ILCT & 258 \\
& $200 \rightarrow 201(0.70)$ & $526(2.35)$ & 0.0002 & LLCT & \\
& $197 \rightarrow 201(0.68)$ & $391(3.17)$ & 0.0564 & MLCT /ILCT & \\
& $197 \rightarrow 206(0.45)$ & $279(4.43)$ & 0.1510 & MLCT/LLCT & \\
& $230 \rightarrow 231(0.51)$ & $569(2.18)$ & 0.0302 & LLCT & \\
& $225 \rightarrow 231(0.66)$ & $392(3.16)$ & 0.1283 & MLCT/ILCT & \\
& $227 \rightarrow 235(0.58)$ & $292(4.24)$ & 0.1360 & MLCT/LLCT & \\
& & & &
\end{tabular}

Table 2: Molecular orbital compositions in the ground state for 1 at the PBE0 level

\begin{tabular}{|c|c|c|c|c|c|}
\hline \multirow[b]{2}{*}{ Orbital } & \multirow[b]{2}{*}{ Energy $(\mathrm{eV})$} & \multicolumn{3}{|c|}{ Composition (\%) } & \multirow[b]{2}{*}{ main bond type } \\
\hline & & $\mathrm{Ir}$ & bpy-D & F-ppy & \\
\hline 197 & -1.356 & 3.4 & 2.9 & 93.7 & $\pi^{*}$ (F-ppy) \\
\hline 192 & -2.144 & 4.0 & 3.1 & 92.9 & $\pi^{*}$ (F-ppy) \\
\hline \multirow[t]{2}{*}{191} & -2.717 & 3.1 & 94.6 & 2.3 & $\pi^{*}($ bpy-D) \\
\hline & \multicolumn{4}{|c|}{ HOMO-LUMO Energy Gap } & \\
\hline 190 & -5.321 & 0.0 & 100 & 0.0 & $\pi(b p y-D)$ \\
\hline 189 & -6.134 & 0.3 & 99.6 & 0.1 & $\pi($ bpy-D) \\
\hline 188 & -6.214 & 48.6 & 3.9 & 47.5 & $\mathrm{~d}(\mathrm{Ir})+\pi(\mathrm{F}-\mathrm{ppy})$ \\
\hline 187 & -6.726 & 26.5 & 3.5 & 70.0 & 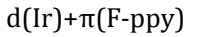 \\
\hline
\end{tabular}


Table 3: Molecular orbital compositions in the ground state for 4 at the PBE0 level

\begin{tabular}{|llllll|}
\hline & & \multicolumn{2}{c}{ Composition (\%) } & \\
\cline { 3 - 5 } Orbital & Energy(eV) & Ir & bpy-D & pqe & main bond type \\
\hline 235 & -1.600 & 0.4 & 38.4 & 61.2 & $\pi^{*}(\mathrm{pqe})+\pi^{*}(\mathrm{bpy}-\mathrm{D})$ \\
232 & -3.020 & 3.6 & 1.5 & 94.9 & $\pi^{*}(\mathrm{pqe})$ \\
231 & -3.042 & 3.8 & 2.1 & 94.1 & $\pi^{*}(\mathrm{pqe})$ \\
& HOMO-LUMO Energy Gap & & & \\
230 & -5.352 & 0.0 & 99.9 & 0.1 & $\pi(\mathrm{bpy}-\mathrm{D})$ \\
229 & -5.865 & 47.7 & 3.4 & 48.9 & $\mathrm{~d}(\mathrm{Ir})+\pi(\mathrm{pqe})$ \\
228 & -6.120 & 0.1 & 99.8 & 0.1 & $\pi(\mathrm{bpy}-\mathrm{D})$ \\
227 & -6.478 & 30.8 & 5.0 & 64.3 & $\mathrm{~d}(\mathrm{Ir})+\pi(\mathrm{pqe})$ \\
225 & -6.769 & 31.9 & 5.6 & 62.6 & $\mathrm{~d}(\mathrm{Ir})+\pi(\mathrm{pqe})$ \\
\hline
\end{tabular}

Table 1 shows that the second absorption band of $\mathbf{1 - 4}$ are at 362(3.42), 385(3.22), 391(3.17), and $392 \mathrm{~nm}$ (3.16 ev), respectively. With respect to 1 , the excitation of MOs $187 \rightarrow 191$ with the configuration coefficient of 0.54 contributes to the absorption at $362 \mathrm{~nm}$. Table 2 shows that MO 187 has $26.5 \% \mathrm{~d}(\mathrm{Ir})$, and $70.0 \% \pi(\mathrm{F}-\mathrm{ppy})$, while MO 191 has 94.6\% $\pi^{*}(\mathrm{bpy}-\mathrm{D})$ composition. Thus the absorption at $362 \mathrm{~nm}$ is mainly attribution to a $[\mathrm{d}(\mathrm{Ir})+\pi(\mathrm{F}-\mathrm{ppy})] \rightarrow\left[\pi^{*}\right.$ (bpy-D)] transition with MLCT/LLCT character, while the absorption of $\mathbf{2}$ at $385 \mathrm{~nm}$ has similar transition character to that of $\mathbf{1}$ at $362 \mathrm{~nm}$. But the absorptions of $\mathbf{3}$ and $\mathbf{4}$ at 391 and $392 \mathrm{~nm}$ has different character. The only difference is the contributes of the LUMO orbit from the $\mathrm{N}^{\wedge} \mathrm{C}$ ligand, thus the absorptions of $\mathbf{3}$ and $\mathbf{4}$ can be described as originating from the $\left[\mathrm{d}(\mathrm{Ir})+\pi\left(\mathrm{N}^{\wedge} \mathrm{C}\right)\right] \rightarrow\left[\pi^{*}\left(\mathrm{~N}^{\wedge} \mathrm{C}\right)\right]$ excited state with different MLCT/ILCT character.

For the third absorption band, the most representative absorption of 1-4 are between $260-292 \mathrm{~nm}$, which have the largest oscillator strength of 0.1 03. According to above analysis, these absorptions is attributed to the $\left[\mathrm{d}(\mathrm{Ir})+\pi\left(\mathrm{N}^{\wedge} \mathrm{C}\right)\right] \rightarrow\left[\pi^{*}\left(\mathrm{~N}^{\wedge} \mathrm{C}\right)\right.$ or $\pi^{*}($ bpy-D)] transition with MLCT/ILCT or LLCT characters. In comparison with those of $\mathbf{1}$, the absorptions of 2-4 are red shifted to some extent. This is due to the strong $\pi$-conjugation effects in 2-4 compared to those of $\mathbf{1}$.

\subsection{Emission spectra of 1-4 in the excited states}

The calculated phosphorescence values of four complexes are at

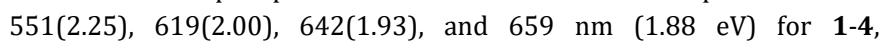
respectively. The excitation of LUMO $\rightarrow$ HOMO- 1 dominates the emissions of 1-4. Upon the above discussion on the frontier molecular orbitals, these emission can be described as a ${ }^{3}\left[\pi\left(\mathrm{N}^{\wedge} \mathrm{N}\right) \rightarrow \pi^{*}\left(\mathrm{C}^{\wedge} \mathrm{N}\right)\right.$ or $\pi^{*}$ (bpy-D)] transition with ${ }^{3} \pi \pi^{*}$ character, which are consistent with the low-energy absorptions in term of transition characters. The energy differences between the calculated low lying absorptions and corresponding phosphorescences are $0.16,0.45,0.42$, and $0.30 \mathrm{eV}$ for $\mathbf{1 - 4}$, respectively, which is consistent with the little change between the ground-and excitedstates structures.

\section{CONCLUSIONS}

In this paper, we investigated the geometry structures, absorptions, and phosphorescent properties of four Ir(III) bipyridyl-phenylenediamine complexes theoretically. Often, the phosphorescent excited state is relevant to both the metal and the ligands, and the frontier molecular orbitals of HOMO and LUMO are dominantly localized on the metal and ligands, respectively. However, in this work, the HOMO are dominantly localized on $\mathrm{N}^{\wedge} \mathrm{N}$ ligand (100\%), while LUMO is contributed by $\pi^{*}$ (bpy-D) or $\pi^{*}\left(\mathrm{C}^{\wedge} \mathrm{N}\right)$ with the $94.1 \%$ composition, therefore, this kind of complex different from traditional transition metal complexes. By comparing the excitation energies of complexes 1-4, we found that the lowest-energy emissions is red-shifted, which is consistent with the increasing trend of the $\pi$-donating ability. At last, we hope that these theoretical studies will assist in the design of highly efficient phosphorescent materials.

\section{ACKNOWLEDGEMENTS}

This work was financially supported by the foundation of state key laboratory of theoretical and computational chemistry (No. 20130023) and the national natural science foundation of china (No. 21405058).

\section{REFERENCES}

[1] Xin, H., Li, F.Y., Shi, M., Bian, Z.Q., Huang, H, C. 2003. Efficient electroluminescence from a new terbium complex [J]. Journal of the American Chemical Society, $125,7166-7167$. doi: $10.1021 / j a 034087 a^{*}$

[2] Yeh, S.J., Wu, M.F., Chen, C.T., Song, Y.H., Chi, Y., Ho, M.H. 2005. New dopant and host materials for blue-light-emitting phosphorescent organic electroluminescent devices [J]. Advanced Materials, 17 (3), 285-289. doi:10.1002/adma.200401373*

[3] Castellano, F.N., Lakowicz, J, R. 1998. A water-soluble luminescence oxygen sensor [J]. Photochemistry and Photobiology, 67, 179-183.

[4] Lakowicz, J.R., Castellano, F.N., Dattelbaum, J.D., Tolosa, L., Rao, G., Gryczynski, I. 1998. Low-frequency modulation sensors using nanosecond fluorophores []]. Analytical Chemistry, 70, 5115-5121.

[5] Law, W.H., Leung, K.K., Lee, L.C. 2014. Cyclometalated iridium (III) bipyridyl-pheny- lenediamine complexes with multicolor phosphorescence: synthesis, electrochemistry, photophysics, and intracellular nitric oxide sensing [J]. Chemmedchem., 9 (6), 1316-1329. doi:10.1002/cmdc. 201400040*

[6] Adamo, C., Barone, V. 1999. Toward reliable density functional methods without adjustable parameters: the pbe0 model. Journal of Chemical Physics, 110, 6158-6170. doi: DOI: 10.1063/1.478522* 